\title{
Fragmentos florestais e manejo sustentável em zona de amortecimento do Parque Estadual da Serra do Mar - Núcleo Santa Vírginia (SP)
}

\author{
João Paulo Villani ${ }^{1}$ \\ Maria de Jesus Robim² \\ Giordano Bruno Automari ${ }^{3}$ \\ ${ }^{1}$ Fundação Florestal \\ pesm.santavirginia@fflorestal.sp.gov.br \\ Rodovia Oswaldo cruz, Km78-Barro Branco -CEP:12140-000-São Luiz do Paraitinga,São \\ Paulo, Brasil \\ 2Instituto Florestal \\ mjrobim@if.sp.gov.br \\ Rodovia Oswaldo cruz, Km78-Barro Branco -CEP:12140-000-São Luiz do Paraitinga,São \\ Paulo, Brasil \\ 3VCP- Votorantin Celulose Papel
}

\begin{abstract}
The main objective of this work was to select forest fragments with potential for the sustainable management in Parque Estadual da Serra do Mar - Núcleo Santa Virgínia buffer zone. Considered as basic principle: the Paraibuna river basis rural community involvement, the surrounding activities will become sustainable and the guarantee and maintenance of biological diversity and the genetics resources from a protect area. The methodology for characterization the area and the community was land visiting, documents source and questionnaire. The use of the SIG - Arc (GIS) 8.1.2 - ESRI, was important for the forest fragment identification. Its results 20 fragments with capacity to implementation the sustainable management inside the buffer zone and $100 \%$ of the landowners agree to participate in the proposal of fragments forest will improve with the Juçara (Euterpe edulis Mart.) palm cultivates.
\end{abstract}

Plavras Chave: fragments, management, buffer zone, fragmentos, manejo, zona de amortecimento.

${ }^{1}$ Este trabalho é parte da dissertação apresentada ao Programa de Pós-Graduação em Ciências Ambientais a UNITAU, intitulada Zona de Amortecimento do Parque Estadual da Serra do Mar - Núcleo Santa Virgínia: subsídios ao Manejo Sustentável dos fragmentos da Mata Atlântica. 


\section{1-Introdução}

O Parque Estadual da Serra do Mar, considerado o detentor da maior porção florestal contínua de Mata Atlântica conservada no Estado de São Paulo, vem sofrendo com as atividades ilegais no interior de suas áreas. A caça e a extração do palmito Euterpe Edulis Martius (Arecaceae), são os principais fatores de impacto sobre a estrutura e dinâmica da floresta mais ameaçada do planeta (SMA,2006).

A extração desses recursos da Mata Atlântica tem causado a redução da biodiversidade e a extinção de espécies. O extrativismo predatório e ilegal da palmeira Euterpe edulis Martius para obtenção do palmito, compromete a sobrevivência da própria espécie quanto de outras da fauna e flora a ela associada (GALETTI E CHIVERS, 1995, REIS et.al.2000,SMA 2006). Assim, a palmeira Juçara já é registrada como "vulnerável à extinção" pela lista de espécies vegetais ameaçadas do Estado de São Paulo.

Pesquisas realizadas por Nodari et.al. (2000), sugerem que a conservação nas áreas de ocorrência natural da palmeira Juçara é a forma mais eficiente contra essa ameaça, especialmente povoamentos existentes no interior das Unidades de Conservação. Neste contexto, estes autores sugerem a manutenção de plantas matrizes reprodutivas (portasementes) nas áreas protegidas e seu entorno, como forma de garantir a manutenção das estruturas genéticas e demográficas das populações naturais de Juçara.

Os remanescentes de Floresta Atlântica localizados em propriedades privadas, geralmente são muito vulneráveis a contínuos distúrbios, sendo de maneira geral, pequenos, isolados e muito perturbados. Existem evidências crescentes de que estes remanescentes não são tão auto-sustentáveis e requerem não apenas a proteção contra distúrbios antrópicos, mas também um manejo ativo para conservar suas populações ameaçadas de extinção (VIANA, 1995).

A Zona de Amortecimento do PESM, criada com a finalidade de amortecimento dos impactos advindos de atividades antrópicas existentes em seu entorno, contempla áreas alteradas ou em bom estado de conservação. De acordo com o Plano de Manejo - "esta zona tem a função de recuperar e proteger a integridade da paisagem e seus recursos hídricos (SMA, 2006).

Desta forma, este trabalho propõe selecionar fragmentos florestais com potencial para o manejo sustentável em propriedades rurais distribuídas na Zona de Amortecimento do Parque Estadual da Serra do Mar - Núcleo Santa Virgínia, bem como identificar a aceitabilidade dos proprietários para incorporar proposta de enriquecimento desses remanescentes florestais com a espécie Euterpe edulis (palmito juçara), como alternativa de renda e redução dos impactos negativos à biodiversidade do Parque Estadual da Serra do Mar.

\section{2- Materiais e Métodos}

\section{1 - Área de estudo}

O Parque Estadual da Serra do Mar (PESM), criado pelo Decreto Estadual $n^{\circ} 10.251$, de 30 de agosto de 1977, possui 315.390 ha. Atualmente, a Gestão do PESM é feita pela Fundação Florestal, a partir de vários núcleos administrativos que se encontra em diferentes níveis de implantação, são eles: Picinguaba, Cunha, Santa Virgínia, Caraguatatuba, São Sebastião, Itutinga Pilões, Curucutu e Itariru.

O Núcleo Santa Virgínia tem como objetivo proteger parte dos remanescentes da Floresta Ombrófila Densa Montana e Automontana no Estado de São Paulo. Sua área está localizada sob as coordenadas geográficas $23^{\circ} 24^{\prime}$ a $23^{\circ} 17^{\prime}$ de latitude sul e $45^{\circ} 03^{\prime}$ de longitude oeste, compreende os municípios de São Luiz do Paraitinga, Natividade da Serra, Cunha e Ubatuba, 
totalizando, aproximadamente 17.000 ha de vegetação nativa, caracterizada pela beleza e abundância de espécies vegetais e animais.

A Vegetação da área está dentro do domínio da Floresta Ombrófila Densa Montana e Automontana, caracterizada sob forma de mosaicos, onde $60 \%$ da área é composta por floresta primitiva ou pouco antropizada, sendo o restante formado por campo limpo, campo sujo, capoeira, capoeirão e reflorestamento de Pinnus spp e Eucaliptus Saligna (TABARELLI et al. 1994).

\section{2 - Procedimentos Metodológicos}

\subsubsection{Mapeamento dos fragmentos florestais}

Para o mapeamento dos fragmentos utilizou-se das informações cartográficas digitalizadas relativas às ortofotos em escala 1:35.000, rede hídrica e limites de municípios retirados das Cartas do IBGE 1:50.000 de 1981 e dados da Cobertura Florestal nativa referente ao Inventário Florestal de 2005. As informações cartográficas foram manejadas no Software ou Programa Arc (GIS), versão 8.1.2 da ESRI, respeitando os limites definidos por município no mapeamento da Zona de Amortecimento. Os fragmentos selecionados foram enquadrados em duas classes distintas em função da legislação ambiental vigente. $\mathrm{O}$ critério de recomendação da área teve como base a Lei Federal 4.771/1965 que instituiu o Código Florestal, e que disciplina as Áreas de Preservação Permanentes - APPs.

Foram recomendados para o manejo sustentado (classe 01), os fragmentos com áreas localizadas fora das zonas de preservação permanente. Para a classe 02 , foram recomendados todos os fragmentos que possuíam áreas totalmente inseridas no interior das áreas de preservação permanente, onde a legislação atual não permite o corte da vegetação, mas possibilita o manejo florestal, como a coleta de sementes (Resolução CONAMA 369/2006).

\subsubsection{Levantamento de campo}

A identificação dos fragmentos em campo foi orientada por meio de mapas fotográficos georeferenciados das microbacias contendo agrupamento de fragmentos. Foram executadas visitas técnicas nas microbacias com a intenção de checar em campo os fragmentos em relação a sua forma e estágios sucessionais da vegetação.

\subsubsection{Seleção das propriedades rurais}

Elaborou-se um questionário semi-estruturado, composto por 25 perguntas dirigidas aos proprietários dos fragmentos selecionados, com o objetivo de buscar informações sobre o perfil do proprietário; analisar as características físicas e as formas de ocupação e manejo da propriedade, bem como identificar o interesse do proprietário em participar da proposta de manejo sustentável do palmito; verificar a presença da espécie Euterpe edulis na área; certificar se o remanescente florestal está protegido através de cercas; aferir a distância da propriedade até a divisa da Unidade de Conservação.

\section{3- Resultados}

\subsection{Mapeamento}


Neste trabalho, o mapeamento da cobertura florestal nativa identificou 772 fragmentos florestais em São Luís do Paraitinga, representando 15.946 hectares, ou seja, 21,6 \% da área total do município que equivale a 73.700 hectares. Em Natividade da Serra, dos 84.800 hectares, foram identificados 1.240 fragmentos, ocupando uma área de 21.776 hectares, ou seja, $25,7 \%$ do total da cobertura florestal nativa existente no município, conforme representados na Tabela 01 .

Para o município de São Luís do Paraitinga, a área do Parque Estadual representa um total de 7.728 hectares ou $10,48 \%$ do município. Do total da cobertura florestal nativa existente no município, 48,46\% esta localizada no interior da unidade. No município de Natividade da Serra, o Parque Estadual corresponde a 10,04 \% da área total do município, equivalente a 8.521 hectares ou $39,14 \%$ da cobertura florestal nativa encontrada no município. Em relação aos municípios estudados, a área protegida contempla, em média, 43,8\% do total da cobertura florestal nativa.

Do total da cobertura florestal nativa encontrada no município de São Luís do Paraitinga, 69,65 \% estão localizados no interior do Parque Estadual da Serra do Mar e Zona de Amortecimento. Em Natividade da Serra, o percentual encontrado foi de 71,86 \%, atestando a grande importância dessa região para a proteção da Floresta Atlântica em relação às demais áreas dos municípios.

Tabela 01 - Cobertura vegetal nativa existente nos municípios de São Luiz do Paraitinga e Natividade da Serra com indicação da porcentagem de áreas de vegetação remanescente encontrada no interior e Zona de Amortecimento do Parque Estadual da Serra do Mar, em relação aos municípios abrangidos.

\begin{tabular}{c|c|c|c|c|c|c|c|c|c}
\hline \multirow{2}{*}{ Municípios } & \multirow{2}{*}{$\begin{array}{c}\text { Área total } \\
\text { do } \\
\text { município } \\
\text { em ha }\end{array}$} & $\begin{array}{c}\text { Área da UC } \\
\text { inseridas nos } \\
\text { municípios }\end{array}$ & $\begin{array}{c}\text { Cobertura } \\
\text { Florestal } \\
\text { Nativa } \\
\text { municipal }\end{array}$ & $\begin{array}{c}\text { Vegetação } \\
\text { nativa no } \\
\text { interior da } \\
\text { UC }\end{array}$ & $\begin{array}{c}\text { Vegetação existente } \\
\text { na UC em relação á } \\
\text { vegetação total do } \\
\text { município }\end{array}$ & $\begin{array}{c}\text { Área } \\
\text { da } \\
\text { Z.A. }\end{array}$ & $\begin{array}{c}\text { Z.A. } \\
\text { x } \\
\text { A.M. }\end{array}$ \\
\cline { 3 - 11 } & ha & $\%$ & ha & $\%$ & ha & $\%$ & 48,46 & 9.463 & 12.83 \\
\hline S.L.P. & 73.700 & 7,728 & 10,48 & 15.946 & 21,6 & 7.728 & ha & $\%$ \\
\hline N.S. & 84.800 & 8,521 & 10,04 & 21.766 & 25,7 & 8.521 & 39,14 & 28.337 & 33.41 \\
\hline
\end{tabular}

Legenda: UC: Unidade de Conservação; SLP: São Luíz do Paraitinga; NS: Natividade da Serra; ZA: Zona de Amortecimento; AM: Área dos Municípios.

Em relação ao número de fragmentos encontrados na zona de amortecimento, foi possível quantificar 132 fragmentos encontrados em São Luís do Paraitinga e 535 no município de Natividade da Serra, totalizando 667 fragmentos. Estes estão localizados em uma faixa com aproximadamente10 km de distância dos limites do PESM - Núcleo Santa Virgínia.

Quanto ao tamanho dos fragmentos, foram encontrados na zona de amortecimento, 442 fragmentos menores que 10 hectares, 160 entre 10 a 30 hectares, 30 entre 30 a 50 hectares e 35 maiores que 50 hectares, o que demonstra significativa fragmentação dos remanescentes florestais da Floresta Ombrófila Densa nos dois município.

\subsection{Seleção dos fragmentos florestais}

Foram selecionados 24 fragmentos florestais, distribuídos aleatoriamente em 18 propriedades rurais, subdivididos em dois grupos de 12 fragmentos, ficando o primeiro grupo localizado no município de Natividade da Serra e o segundo grupo no município de São Luís do Paraitinga (Figura 01). Foram priorizadas e mapeadas 06 microbacias inseridas na bacia hidrográfica do Rio Paraibuna nos municípios de São Luiz do Paraitinga e Natividade da Serra. Em cada microbacia foram escolhidos grupos de fragmentos, onde um deles será escolhido para ser o projeto demonstrativo junto à comunidade local residente na microbacia. 
As microbacias Ponte Alta e Campo Grande estão situadas na bacia hidrográfica do Rio Paraibuna e a microbacia do Caeté está situada na bacia hidrográfica do Ribeirão da Cachoerinha, sub-bacia do rio Paraitinga. A distância média das microbacias em relação à UC é de 2,97 Km. No caso da Ponte Alta a distância da UC é de 950 metros, em média, porém pela existência de fragmentos vizinhos à área protegida, esta microbacia foi contemplada, conforme apresenta a (Tabela 02).

Tabela 02 - Caracterização das microbacias e fragmentos selecionados de acordo com os critérios adotados para o mapeamento das áreas no município de São Luiz do Paraitinga

\begin{tabular}{l|c|c|c|c|c|c}
\hline \multirow{2}{*}{ Características } & \multicolumn{6}{c}{ Microbacias em São Luiz do Paraitinga } \\
\cline { 2 - 7 } & $\begin{array}{c}\text { Ponte } \\
\text { Alta }\end{array}$ & $\begin{array}{c}\text { Campo } \\
\text { Grande }\end{array}$ & Caeté & Total & MDMUC & TMF(ha) \\
\hline Distância média da UC em Km & 0,95 & 3,31 & 4,66 & - & 2,97 & - \\
\hline Integrada em projetos de microbacias & - & - & $\mathrm{x}$ & 1 & - & - \\
\hline $\begin{array}{l}\text { Área total dos fragmentos escolhidos } \\
\text { (ha) }\end{array}$ & 79,6 & 111,5 & 146,12 & 337,22 & - & 112,4 \\
\hline $\begin{array}{l}N^{\circ} \text { do fragmento definido como } \\
\text { projeto piloto }\end{array}$ & 2 & 4 & 4 & 3 & - & - \\
\hline
\end{tabular}

Legenda: UC: Unidade de Conservação; MDMUC: Média das Distâncias entre as Microbacias e a Unidade de Conservação; TMF (ha): Tamanho Médio dos Fragmentos (ha)

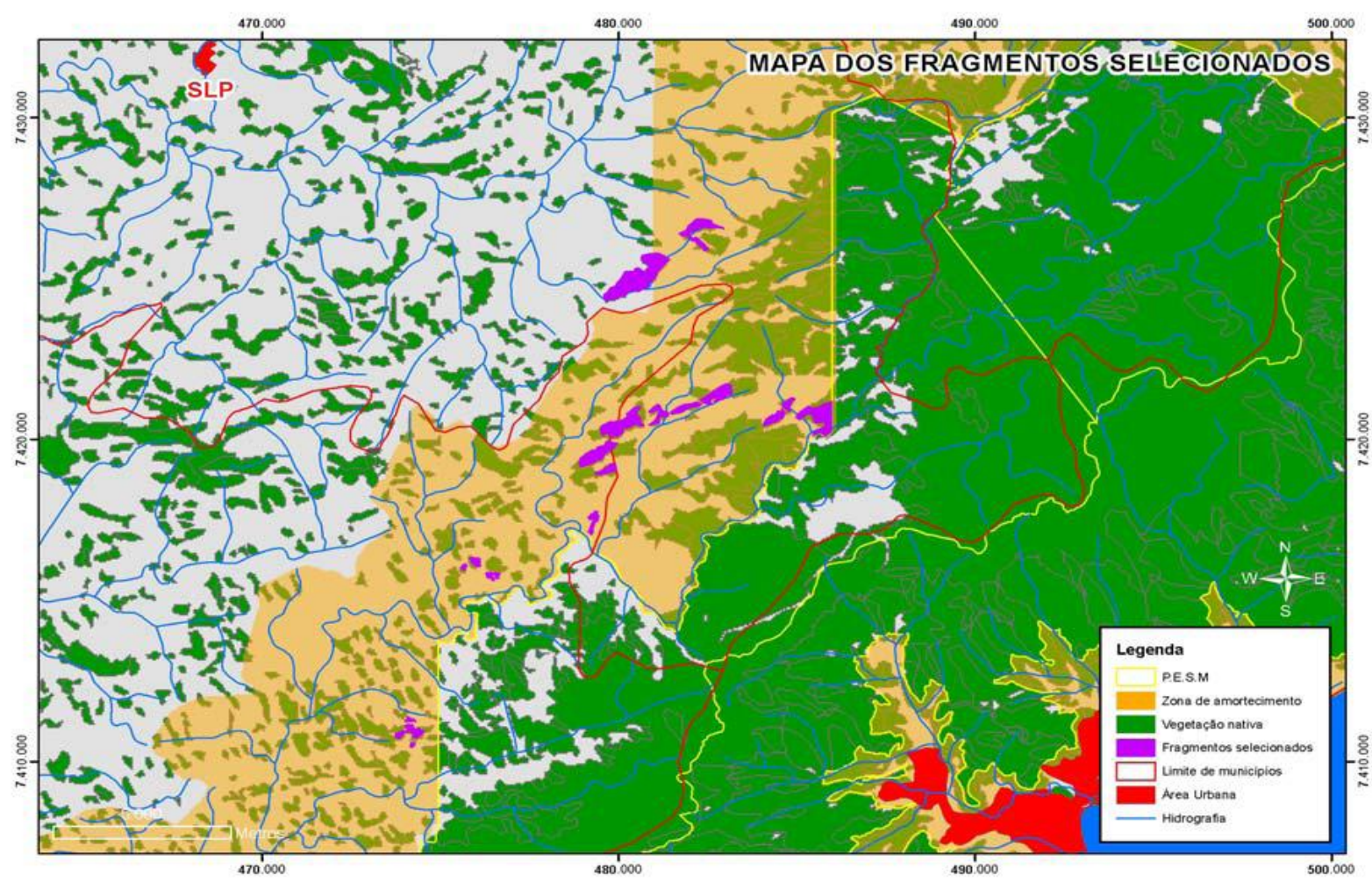

Figura 01 - Detalhamento dos fragmentos selecionados no interior da Zona de Amortecimento e respectivos municípios

\subsection{Características das Propriedades Rurais Selecionadas}

Dos 24 fragmentos selecionados, 12 estão situados no município de natividade da Serra e 12 em São Luiz do Paraitinga. Todos estes fragmentos encontram-se localizados em dezoito propriedades rurais e distribuídos em 6 microbacias, sendo 7 propriedades rurais 
pertencentes ao município de Natividade da Serra e 11 ao município de São Luiz de Paraitinga.

Os resultados dos questionários mostraram grande receptividade e aceitação por parte dos proprietários para participar do processo de implantação de uma proposta de manejo sustentável utilizando a espécie Euterpe edulis, a contabilização das respostas à esta pergunta foi de $100 \%$ de adesão .

O uso do fogo para manutenção das pastagens ainda permanece presente na cultura da população local nos municípios estudados, sendo identificadas três propriedades que ainda fazem o manejo do pasto utilizando as queimadas e 11 que foram queimadas por fogo do confrontante. Em São Luís do Paraitinga 72,72 \% das propriedades rurais estudadas foram queimadas e, em Natividade da Serra, 85,71\% (Tabela 03).

Do total, apenas 06 proprietários desenvolvem atividades rurais sustentáveis. Como atividades menos impactantes, a silvicultura e a apicultura estão presentes. A identificação de uma propriedade, transformada em Reserva Particular do Patrimônio Nacional (RPPN), desperta na zona de amortecimento a importância da conservação das áreas naturais para uma nova modalidade de desenvolvimento sustentável, o ecoturismo.

Embora as propriedades possuam áreas florestadas, os resultados dos questionários apontaram que $100 \%$ delas, não possuem reserva legal averbada, como determina o Código Florestal Brasileiro Lei Federal nº 4.771/1965.

Tabela 03 - Relatos sobre o uso do fogo nas 18 propriedades rurais selecionadas nos municípios de São Luiz do Paraitinga e Natividade da Serra.

\begin{tabular}{c|c|c|c|c|c|c}
\hline \multirow{2}{*}{ Uso do Fogo como Prática Agrícola } & \multicolumn{5}{c}{ Microbacias } \\
\cline { 2 - 6 } & São Luiz do Paraitinga & \multicolumn{2}{c}{ Natividade da Serra } \\
\cline { 2 - 6 } & Sim & Não & Total & Sim & Não & Total \\
\hline Utiliza a prática do fogo & 2 & 9 & - & 1 & 6 & - \\
\hline $\begin{array}{c}\text { A propriedade foi queimada pelo fogo do } \\
\text { confrontante }\end{array}$ & 6 & 5 & - & 5 & 2 & - \\
\hline Total de propriedades acometidas pelo fogo & 8 & - & 11 & 6 & - & 7 \\
\hline Total (\%) & \multicolumn{3}{|c|}{72,72} & & 85,71 \\
\hline
\end{tabular}

Quando perguntado aos entrevistados sobre o desaparecimento do palmito nos fragmentos florestais, estes responderam que os principais motivos foram: uso do fogo, extração ilegal, desmatamento para formação de pastagem e subsistência.

\section{Discussão}

O mapeamento dos fragmentos da microbacia Ponte Alta indica que a área possui fragmentos ou contínuos florestais ligados ao maciço florestal do Parque Estadual da Serra do Mar, permitindo a translocação do fluxo gênico, sendo possível detectar a presença do Euterpe edulis em todos os fragmentos selecionados nesta área.

Porém, outros fragmentos selecionados na microbacia do Caeté não registram a presença do palmito Juçara, o que vem ratificar a hipótese da falta de conexão entre os fragmentos existentes nesta bacia em relação às demais.

Outra característica importante identificada nos fragmentos da zona de amortecimento foi a ausência de florestas nativas nas margens dos rios e córregos existentes nas microbacias estudadas. Considerando a importância da mata ciliar como corredor ecológico, este é mais um fator que contribui para o isolamento das áreas exportadoras e mantenedoras do fluxo gênico para áreas de baixa variabilidade genética ou menor potencial biológico. A falta de 
corredores de ligação é um dos fatores que dificulta a translocação da fauna de uma microbacia para outra, bem como entre o agente exportador de biodiversidade - o Parque Estadual da Serra do Mar.

Neste contexto, a fragmentação das formações florestais somadas ao corte ou extração seletiva, tem propiciado o desaparecimento de espécies florestais. A espécie Euterpe edulis foi encontrada em somente quinze fragmentos selecionados nas microbacias, indicando sua vulnerabilidade e constante risco de extinção. Kageiama et al. (2003), afirmou que as conseqüências da fragmentação da paisagem se refletem na perda de conectividade, redução de biodiversidade e risco eminente de extinção de espécies.

Alguns proprietários apontaram que o desaparecimento do Juçara ocorreu há mais de 60 anos nestas áreas e, em outras, o número de árvores adultas reprodutivas é extremamente pequeno, não garantindo o desenvolvimento da espécie ao longo do tempo por falta de variabilidade genética ou pela extração dos adultos reprodutivos e não reprodutivos, impossibilitando a perpetuação de descendentes.

A atividade pecuária tem demonstrado, em função do manejo inadequado ao longo dos anos, colaborar com o processo de extinção do Juçara. Atualmente, pelo fato de alguns fragmentos estarem sem cercas de contenção tem possibilitado a entrada de animais domésticos que possuem hábitos alimentares seletivos, como os eqüinos e os bovinos, contribuindo para a erradicação de algumas espécies, como o Palmito.

A partir dos resultados deste trabalho é indicado que a palmeira Juçara seja escolhida como espécie vegetal para o enriquecimento dos fragmentos selecionados para o manejo sustentável em áreas do entorno do Núcleo Santa Virgínia. Considerada espécie chave para o ambiente, tem grande importância na dinâmica da floresta Ombrófila Densa Montana e Automontana, contribuindo em muito na oferta de alimento para fauna, uma vez que é considerada espécie zoocórica, conforme afirmou (Reis, 1995, GALLETTI, M.; CHIVERS,1995). Quanto aos aspectos econômicos, agrega valor monetário aos remanescentes, estimulando a conservação da biodiversidade da Mata Atlântica em áreas que sofrem com a exploração predatória.

\section{Conclusões}

Os resultados deste trabalho permitiram concluir que:

- os remanescentes de florestas nativa selecionados na zona de entorno são importantes para a formação dos corredores ecológicos entre a área protegida e seu entorno, garantindo assim, o restabelecimento da conectividade entre as áreas de produção e áreas de proteção integral.

- a implantação de um novo modelo regional de gestão ambiental sustentável deve ser prioridade para essas áreas, onde o planejamento e a vocação da região devem ser respeitados, adotando ações que promovam o desenvolvimento rural voltados à recomposição e manejo da paisagem, considerando que a unidade de conservação é o componente mais importante deste contexto para a conservação da biodiversidade da Mata Atlântica.

- a espécie Euterpe edulis é a indicada para o manejo sustentável dos fragmentos pelo seu grande potencial ecológico e produtivo na Floresta Atlântica, bem como pela grande aceitabilidade (100\%) dos proprietários, motivada principalmente, pela cultura local. 


\section{6- Referências}

GALLETTI, M.; CHIVERS, D. J. Palm harvest threatens Brazil's best protected area of Atlantic Forest. Oryx, vol. 29, p.225-226, 1995.

KAGEIAMA, P. Y. et al. Restauração ecológica de ecossistemas naturais. Botucatu: FEPAF, 2003. 340 p.

KRONKA,F.J.N et al. Inventário florestal da Vegetação Natural do Estado de São Paulo. São Paulo: Instituto Florestal, 2005. 200 p.

NODARI, R. O.; M. S.; REIS, A.; GUERRA, M. P. Euterpe edulis Martius (Palmiteiro) biologia: conservação e manejo / Editores: Maurício Sedrez dos Reis, Ademir Reis. Itajaí: Herbário Barbosa Rodrigues, 2000. p. 304-323.

Planos de Manejo das Unidades de Conservação: Parque Estadual da Serra do Mar - Núcleo Santa Virgínia Plano de Gestão Ambiental - fase 1, Secretaria do Meio Ambiente / Coordenadoria de Informações Técnicas, Documentação e Pesquisa Ambiental, Instituto Florestal, Fundação Florestal; Organizado por João Paulo Villani, Rosely Alvim Sanches, C. Maretti, Sidnei Raimundo...[et al]. - São Paulo: SMA, 1998. $128 \mathrm{p}$.

REIS, M. Dispersão de sementes de Euterpe edulis Martius - (palmae) em uma floresta ombrófila densa montana da encosta atlântica, SC. Tese de Doutorado, Instituto de Biologia Universidade de Campinas, São Paulo, 1995.

SÃO PAULO,2006.Parque Estadual da Serra do Mar - Plano de Manejo. Secretaria de Meio Ambiente.São Paulo.441p.

TABARELLI,M.,VILLANI,J.P. \& MANTOVANI, W. Estudo comparativo da vegetação de dois trechos de floresta secundária no Núcleo Santa Virgínia/SP. Revista do Instituto Florestal. São Paulo, 1994. 6(1): $1-11 \mathrm{p}$.

VIANA, V. M. Conservação da biodiversidade de fragmentos florestais em paisagens tropicais intensamente cultivadas. In: Abordagem interdisciplinar para a conservação da biodiversidade e dinâmica do uso da terra, Belo Horizonte, 1995.p.135-154. 